\title{
İskelet displazileri ile birlikte olan spinal patolojiler - displazilerde spinal sorunlar
}

\section{Spinal pathologies associated with skeletal dysplasias -spinal problems of dysplasia}

\author{
Hacı Mustafa Özdemir ${ }^{1}$, Osman Yüksel Yavuz ${ }^{2}$ \\ ${ }^{1}$ Acıbadem Hastanesi, Ataşehir, İstanbul \\ ${ }^{2}$ Yüzyıl Hastanesi, Pendik, İstanbul
}

\begin{abstract}
İskelet displazileri, kemik ve/veya kıkırdağın büyüme ve gelişmesindeki anomalilerin neden olduğu heterojen bir grup hastalıktır. Her ne kadar iskelet displazilerinin çoğu nadir olsa da, grup olarak ele alındıklarında pediatrik ortopedi veya spinal deformite kliniklerinde oldukça sık rastlanır ve 10.000 doğumun 2,4'ünde görülür. Displazilerin çoğu, belirgin bir yaştaki ortalama boy uzunluğunun iki standart deviyasyon altında boy kısalığı ile kendini gösterir. İskelet displazilerinin 2010 yılında yapılan sınıflamasında 456 değişik iskelet displazisi belirlenmiş ve bunların 316'sının, toplam 226 değişik genin en az birindeki değişiklikle ilişkili olduğu tespit edilmiştir. İskelet displazisi hastalarında spinal manifestasyonlar sıktır. Çoğu için özgün spinal karakteristikler olmakla birlikte, ortak birçok özellikleri vardır; dolayısıyla, 456 displazinin hepsini tek tek ele almak yerine gruplar halinde tartışmak mümkün olmaktadır. Spinal deformite gözlenen iskelet displazileri arasında akondroplazi, kondroplaziya punktata, diastrofik displazi, Kniest displazisi, Larsen sendromu, metafizyel kondroplaziler, metatrofik cücelik, mukopolisakkaridozlar, psödoakondroplazi, spondiloepifizyel displazi konjenita ve tarda, ve spondiloepimetafizyel displazi sayılabilir. En sık görülen spinal anomaliler arasında atlanto-aksiyel instabilite ve odontoid hipoplazi, servikal kifoz, torakolomber kifoz, skolyoz, foramen magnum stenozu ve spinal stenoz sayılabilir.
\end{abstract}

Anahtar sözcükler: iskelet displazisi; skolyoz; torakolumbar kifoz; gibbus

İskelet displazisi hastalarında farklı birkaç spinal anomali görülür. En sık görülen spinal anomaliler arasında atlanto-aksiyel instabilite ve odontoid hipoplazi, servikal kifoz, torakolomber kifoz, skolyoz, foramen magnum stenozu ve spinal stenoz sayılabilir. İskelet displazileri, spinal deformite cerrahlarının tedavi ettiği en zor problemlerin bir bölümünü oluşturur. Deformiteler ileri derecede, kemik distorsiyonu

\begin{abstract}
Skeletal dysplasia is a heterogeneous group of diseases caused by anomalies in the growth and development of bone and/or cartilage. Although skeletal dysplasia is rare, it is quite common in pediatric orthopedics or spinal deformity clinics when taken as a group and occurs at 2,4 of 10,000 births. Most of the dysplasia manifests itself with a short height under two standard deviations of a mean age length at a significant age. In the 2010 classification of skeletal displasia, 456 different skeletal dysplasia were identified and 316 of them were found to be associated with a change in at least one of 226 different genes. Spinal manifestations are common in patients with skeletal dysplasia. Although most of them have unique spinal characteristics, there are many common features; so it is possible to discuss all of the 456 displasies in groups instead of individually. Among the skeletal dysplasia observed, chondroplasia, chondroplasia punctata, diastrophic dysplasia, Kniest dysplasia, Larsen syndrome, metaphyseal chondroplasia, metatrophic dwarfism, mucopolysaccharidoses, pseudoachondroplasia, spondyloepiphyseal dysplasia congenita and tarda, and spondyloepymetaphysial dysplasia can be considered as spinal deformities. The most common spinal anomalies include atlanto-axial instability and odontoid hypoplasia, cervical kyphosis, thoracolumbar kyphosis, scoliosis, foramen magnum stenosis and spinal stenosis.
\end{abstract}

Key words: skeletal dysplasia; scoliosis; thoracolumbar kyphosis; gibbus

belirgin, tespit noktaları küçük ve ulaşımı zor, kemik yumuşak ve deformiteler rijiddir; küçük ölçekli implantlar gerekebilir ve pulmoner restriksiyon gibi sekonder medikal problemler birçok displazide sorun oluşturabilir. Bu hastaların çoğu, küçük hava yolu, hava yolu bağ dokusu bozuklukları, şekli bozulmuş göğüs yapısı ve restriktif akciğer hastalığı gibi belirgin anestetik riskler taşır. Bu hastalar ayrıca, ameliyat

- İletişim adresi: Doç. Dr. Osman Yüksel Yavuz, Fevzi Çakmak Mah., Tevfik İleri Cad., No: 105 Pendik, İstanbul Tel: 0216 - 3975900 e-posta: oyyavuz@yahoo.com

- Geliş tarihi: 8 Ağustos 2016 Kabul tarihi: 8 Ağustos 2016 
masasında pozisyon verirken bile geliş̧ebilecek, cerrahi sırasında aşırı artmış nörolojik riskler taşırlar. Cerrahların, hastanın cerrahi öncesi nörofizyolojik çalışmalar ile elde edilen referans değerlerini göz önüne alarak, anestezinin indüksiyonundan sonra hastaya pozisyon verilmeden önce nöromonitorizasyonu başlatması gerekir.

Servikal vertebra, iskelet displazilerinde sıklıkla tutulur. Tüm iskelet displazilerinde servikal vertebra grafisi temin etmenin genel kural olması yanında, anomalileri veya genel eklem laksisitesi olanlarda fleksiyon ekstansiyon görüntüleri almak da gerekir. En sık görülen problemler; çoğunlukla odontoid hipoplazi ile görülebilen atlanto-aksiyel instabilite (spondiloepifizyel displazi, Kneist, mukapolisakkaridozis, psödoakondroplazi, Stickler sendromu ve metotropik displazi), servikal kifoz (diastrofik displazi, kamptomelik displazi ve larsen sendromu), ve servikal stenozdur (akondroplazi, metatrofik displazi ve Jeune sendromu).

\section{Atlanto-aksiyel İnstabilite ve Odontoid Hipoplazi}

Odontoid hipoplazi ve atlanto-aksiyel instabilite ile ilişkili iskelet displazisi olan hastalar herhangi bir cerrahi işlem için başvurduğunda, servikal vertebra mutlaka değerlendirilmelidir. Atlanto-aksiyel instabilite ile sıklıkla ilişkili olan iskelet displazileri arasında; Conradi-Hünermann sendromu (kondroplazi punktata altgrubu), Kniest displazisi, metafizyel kondrodisplazi (McKusick ve Schmid tipleri), metatrofik cücelik, Morquio sendromu, psödoakondroplazi, sponiloepifizyel displazi konjenita ve tarda sayılabilir.

Atlanto-aksiyel instabilite servikal miyelopatiye yol açabilir ve kendini progresif olarak dayanıklılığın azalması ve üst motor nöron semptomları (hiperrefleksi, klonus, pozitif Babinski işareti ve spastisite) ile gösterir. Ancak, iskelet displazisi olan çocuklarda atlanto-aksiyel instabilitenin neden olduğu miyelopati, genel yorgunluk, ekstremitelerde belirsiz ağrılar, sabah uyandığında ekstremiteleri hareket ettirememe, yürümede zorluk ve açıklanamayan paroksismal takipne gibi anormal belirtilerle kendini gösterebilir. Bitkinlik, genellikle nörolojik belirtilerden önce ortaya çıkar. Düz grafilerle odontoid hipoplazisi veya aplazisi saptanabilirken, lateral fleksiyon-ekstansiyon servikal grafiler ile atlanto-aksiyel instabilite teşhisi konulabilir.

Atlantodens aralığı $8 \mathrm{~mm}$ üzerinde olanlar veya nörolojik tehlikesi bulunanlarda C1-C2 artrodezi endikasyonu vardır. Translasyon $5-8 \mathrm{~mm}$ arasın$\mathrm{da}$ ise fleksiyon ve ekstansiyonda servikal manyetik rezonans (MR) görüntüleme gereklidir ve fleksiyonekstansiyon MR'ı omuriliğin tehlikede olduğunu gösterirse artrodez gerçekleştirilir. Spinal kanalın $14 \mathrm{~mm}$ altında olduğu durumlarda da C1-C2 artrodezi düşünülür. Gerektiği durumlarda C1-C2 laminektomisi ve foramen magnum genişletmesi yapılabilir. Kısa boylu hastalarda servikal vertebranın internal tespiti kablolar, lateral gövde vidaları, pedikül vidaları vaye C1-C2 intraartiküler vidaları ile yapılabilir. Başarılı bir artrodez için otojen kemik grefti tercih edilir.

\section{Servikal Kifoz}

Servikal kifoz çoğunlukla anterior yetmezlikler, posterior spondilolizis, spondilolistezis ve ossifikasyon defektleri ile birlikte görülür. Servikal kifoz diastrofik displazi ve Larsen sendromu hastalarında görülebilir. Ancak, diastrofik displazi hastalarında spontan rezolüsyon gelişme potansiyeli yüksek olduğundan, bu displazilerdeki kifozun doğal seyri belirgin olarak diğerlerinden farklıdır. Her ne kadar Finlandiya'da diastrofik displazili geniş bir kohort grubunda servikal kifozisli birçok hastada spontan rezolüsyon gösterilmiş olsa da, erken füzyon geç görülen ileri derece deformiteleri engelleyebilir. Ne yazık ki geç deformiler ağır olabilir ve geniş anteroposterior stabilizasyon ve re-alignment gerektirebilir. Nörolojik bulgu veya semptomların olduğu durumlarda veya breyse rağmen kifozun progresyona devam etmesi durumunda cerrahi endikasyonu vardır. Cerrahi tedavi, posterior servikal spinal artrodez ve eğer anterior kompresyon varsa anterior dekompresyonu içerir. İleri derece spinal kord kompresyonu veya miyelopati varlığı, korpektomi ve destek grefti yapılmasını gerektirir. Pedikül boyutu izin verirse enstrümantasyon kullanılır. Otojen kemik grefti iliak kemikten elde edilir. Eğer daha fazla kemik ihtiyacı doğarsa, femur veya tibia kaynak olarak kullanılabilir.

Kemik displazisi olmasına rağmen otojen iliak greft ile füzyon, atlanto-aksiyel instabilitede çoğunlukla başarılıdır, ancak kifozda başarılı olma ihtimali düşüktür. Diyastropik displazide $60^{\circ}$ altındaki kifozlar tipik olarak spontan düzelir, ancak progresyon açısından takip edilmelidir. Daha ileri kifozlar, progresif ise posterior füzyon ile ağır ise anterior korpektomifüzyon / posterior füzyon ile tedavi edilmelidir. Larsen sendromunda kifoz aynı doğal sürece sahip değildir; hastalar, kifoz daha ağırlaşmadan, hafif derece olduğu dönemde posterior füzyon ile tedavi edilmelidirler. Enstrümantasyon vertebranın boyutuna bağlıdır ve yeterli ve güvenli stabilizasyon elde edilmelidir. Yazar, deformitenin zamanla düzelebilmesi için, anterior büyümenin olduğu alanlarda enstrümantasyon kullanmamıştır. 


\section{Torakal ve Torakolomber Kifoz}

Torakal veya torakolomber kifoz birçok iskelet displazisinin klinik tablosunda yer alır: akondroplazi, Conradi-Hunermann sendromu, diastrofik cücelik, metatrofik cücelik, mukopolisakkaridozlar ve spondiloepifizyel displazi.

Akondroplazide torakolomber skolyoz tipik olarak düzelir. Diğer displazilerdeki kifozların doğal seyri olumlu değildir. Illerleyen kifozda, anterior ve posterior füzyon yapmak gerekir.

\section{Skolyoz}

Skolyoz birçok iskelet displazisi ile birlikte olabilir. Kondrodisplazi punktata, diastrofik cücelik, metatrofik cücelik, Morquio sendromu, psödoakondroplazi, spondiloepifizyel displazi konjenita ve spondiloepimetafizyel displazi bunların arasında sayılabilir.

Eğriliğin tipi ve doğal öyküsü, ilişkili olduğu iskelet displazisine göre değişkenlik gösterir. Genel olarak, iskelet displazileri ile birlikte olan skolyoz tedavi ilkeleri idiyopatik skolyoz ile benzerlik gösterir. Eğriliği $25-45^{\circ}$ arasında olan hastalarda breys endikasyonu, $50^{\circ}$ üzerinde olanlarda ise posterior spinal artrodez endikasyonu vardır. Uzayan rod enstrümantasyonu veya anteroposterior artrodez genç hastalarda gerçekleştirilebilir. Krankşaft fenomenini ve eğrilik ilerlemesini engellemek için, kalıcı füzyon hasta büyüyene kadar ertelenir.

\section{Foramen Magnum Stenozu}

İskelet displazisi olan hastalarda, spinal deformite ve instabilitesine ek olarak, spinal kanalda darlık gelişebilir. Stenoz tüm kanal boyunca görülebilir. Foramen magnum stenozu akondroplazi ve hipokondroplazi hastalarında görülebilir.

Foramen magnum seviyesindeki stenozun en sık semptomu aşırı horlama ve apnedir. Stenoz, kifoz veya instabilitenin neden olduğu miyelopatinin tespiti, spastisite gösterecek kadar yeterince miyelinize olmamış olan bebek ve küçük çocuklarda zor olabilir. Uyku çalışmaları yardımcı olabilir. Kooperasyon kurduğunuz bir radyoloğunuz varsa fleksiyon-ekstansiyon manyetik rezonans görüntüleri yardımcı olabilir, ancak çoğu radyolog anestezi altındaki hastalardan fleksiyon-ekstansiyon görüntüleri almakta isteksizdir. Stenoz ayrıca, alt kraniyal sinir disfonksiyonu, hiperrefleksi, hipotoni, zayıflık veya parezi, klonus ve yutkunma güçlügü gibi diğer kronik boyun sapı kompresyonu belirtilerine de neden olabilir; gelişim geriliğine de yol açabilir. En önemlisi, foramen magnum stenozu ani ölüme neden olabilir. Bu nedenle, tanı konulması kritik öneme sahip olup uyku testi ve MR ile yapılabilir. Tedavi cerrahi dekompresyondur.

\section{Spinal stenoz}

Foramen magnumdaki stenozun yanında, iskelet displazisi hastalarında daha distal seviyelerde de spinal stenoz gelişebilir. Spinal stenoz akondroplazi ve Conradi-Hünermann sendromu hastalarında görülebilir. Spinal stenozun başlangıç tedavisi konservatifdir. Cerrahi endikasyonlar arasında; progresif semptomlar, idrar retansiyonu, 200 metre sonra şiddetli klaudikasyo ve istirahat halinde nörolojik semptomlar görülmesi sayılabilir.

\section{Küçük Toraks}

Küçük toraksla birlikte seyreden, ancak sıklıkla tespiti yapılamamış birçok iskelet displazileri bulunmaktadır. Bunlar arasında; simetrik kısa ekstremiteler ve daralmış toraks ile karakterize olan Jeune sendromu veya diğer bir ismiyle boğucu torasik displazi; segmentasyon defektleri, multipl kaburga füzyonları ile karakterize, notch sinyal yolağı ile ilişkisi tespit edilmiş, orta derece solunum sıkıntısına neden olan spondilokostal displazi (küçük hücre değişimli displazi veya Jarcho-Levin sendromu); ve Porto Riko'lu ailelerde gözlenen, segmentasyon defektleri ve posterior kaburga füzyonu ile karakterize, notch sinyal yolağı ile ilişkisi tespit edilmiş, ileri derece solunum sıkıntısına neden olan, ancak \% 25 'i yetişkin döneme kadar rahat yaşayabilen spondilotorasik displazi (spondilotorasi dizostozis veya Lavy-Moseley sendromu) sayılabilir. Bu hastalıklarda, toraks volümünü arttırmak amacıyla, vertikal genişleyebilen prostetik titanyum kaburga ile ekspansiyon torakoplasti uygulanmaktadır.

\section{DISPLAZILERIN SINIFLANDIRILMASI}

İskelet displazileri değişik metodlarla sınıflandırılmaktadır. Metodlardan biri, vücut asimetrisine göredir: kısa ekstremite ve kısa gövde. Kısa ekstremite tipleri ayrıca, kısa segmentin bulunduğu ekstremitenin bölümüne göre de sınıflandırılır: proksimal (rizomelik), orta (mezomelik) ve distal (akromelik). Diğer bir metod, displaziye neden olan genetik defekte göre sınıflama yapılmasıdır. Son olarak, iskelet displazileri spinal deformite bulunup bulunmamasına (multipl epifizyel displazi gibi) göre de sınıflandırılabilir. Spinal deformite ile seyreden iskelet displazileri de; akondroplazi, diastrofik displazi, psödoakondroplazi, kollajen sentezindeki mutasyona sekonder displaziler, mukopolisakkaridozlar ve diğer iskelet displazileri olarak sınıflandırılır. 


\section{Akondroplazi}

Akondroplazi, 30.000 kişide bir insidans ile en sık iskelet displazisidir. Akondroplazinin nedeni, fibroblast büyüme faktörü reseptöründeki bir mutasyon neticesinde enkondral kemik formasyonundaki defekttir. Otozomal dominant geçiş gösterir. Rizomelik kısa boy, trident el, genu varum ve dirsekte fleksiyon kontraktürü iskelet bulgularıdır. Medikal komplikasyonları arasında; sık orta kulak iltihabı, obstrüktif uyku apnesi, azalmış solunum dürtüsü, azalmış solunum fonksiyonu ve hidrosefali sayılabilir. Akondroplazinin spinal bulguları arasında; torakolomber kifoz, foramen magnum stenozu ve spinal stenoz sayılabilir.

Akondroplazide gözlenebilecek ilk spinal bulgu foramen magnum stenozudur ve hayatın ilk iki yılında ortaya çıkabilir. Stenoz, doğumda nispeten küçük olan foramen magnumun enkondral ossifikasyondaki aksaklık nedeni ile hayatın ilk yılında gelişmesinde gerilik olması nedeniyle gelişir. Foramen magnum stenozu cerrahi dekompresyon ile tedavi edilir. Her ne kadar semptomatik olan hastaların büyük bölümü hayatın ilk iki yılında dekompresyona ihtiyaç duysa da, semptomlar daha ileri yaşta da kendini gösterip tedaviye ihtiyaç doğurabilir. Dekompresyon, genç hastalarda C1'e kadar uzanırken daha ileri yaşlarda T4'e kadar uzanır.

Bagley ve ark., foramen magnum stenozu için servikomedüller dekompresyon yapılan 43 akondroplazi hastasını (ortalam yaş 5 yıl 10 ay, 2-199 ay) değerlendirdiler. Bebeklerde solunum semptomlarının düzelmesi dekompresyonun hemen ardından gerçekleşti. Komplikasyon olarak; yedi hastada serebrospinal sıvı sızıntısı, beş hastada revizyon cerrahisi gerektiren tekrarlayıcı stenoz ve dört hastada enfeksiyon gözlendi.

Gelişim sürecinde gelişen ikinci spinal bulgu torakolomber kifozisdir. Torakolomber kifoz, akondroplazide sık gözlenir ve 1-2 yaşında insidansı \%87'dir. Akondroplazi hastaları yenidoğan döneminde iken, torakolomber kifoz tipik olarak $20^{\circ}$ 'dir. Bebekler oturmaya başladıklarında (6-18 aylarda), sıklıkla hipotoni ile birlikte normalden geniş kafa ve şiş karınla öne doğru yığılırlar. Bu devam ettikçe kifoz artar ve vertebra anteriorunda kamalaşma gelişir. Bu kifozların çoğu, gövde güçlendikçe ve bebek yürümeye başladıkça, 12-18 aylarda düzelmeye başlar. Bu doğal seyir nedeni ile, kifoz insidansı 2-5 yaşlarda \%39'a ve 5-10 yaşlarda \%11'e düşer.

Kifoz gelişimini engellemek için, bebeklerin desteksiz oturması ve destekli de olsa $60^{\circ}$ 'den daha dik oturması engellenir. Kifozu devam eden hastalarda; deformitede progresyon, kalçada fleksiyon kontraktürü ve hiperlordoz görülebilir. Ayrıca, kifozun devam etmesi, beraberindeki spinal stenozun şiddetinin artmasına yol açar.

Kifoz ilerliyor veya vertebrada kamalaşmaya yol açıyor ise breys kullanımı düşünülmelidir. Breys kullanımı, kamalaşma geçene ve kifozu azalana dek devam ettirilir. Pauli ve ark. tarafından tedavi edilen 66 hastanın hiçbirinde oturma değişiklikleri ve gerektiğinde breys kullanımı ile kifoz progresyonu görülmemiştir. Ancak, kısa boylu ve hipotonik çocuklarda breys kullanımı sık düşmelere ve azalmış mobiliteye neden olur. Bu nedenle, bu tip hastalarda breys her zaman uygulanmaz.

Vertebra kamalaşması veya kifoz devam ettiğinde cerrahi endikasyon doğar. Persistan kifozun doğal seyri tam olarak tanımlanamamıştır, ancak $50^{\circ}$ üzerindekiler sıklıkla nörolojik semptomlar ile seyreden rijid açılı kifoza ilerler. Bu nedenle, nörolojik riskle birlikte kifoz veya $50^{\circ}$ üstünde kifoz varlığında cerrahi endikasyon bulunur. Cerrahi tedavide, posterior artrodez veya anterior ve posterior artrodez yapılabilir. Anteroposterior cerrahi için endikasyonlar arasında; anterior sıkışma ve pedikül vidaları için pedikül çapının yetersiz olması sayılabilir. Anterior sıkışma varsa destek grefti ile birlikte anterior korpektomi yapılabilir. Spinal stenoz varsa laminektomi gerçekleştirilir. Posterior enstrümantasyon için, spinal kanalın darlığından dolayı tel ve hook'lar kontendike olması nedeniyle, pedikül vidaları tercih edilir. Eğer sakrum dekompresyon ile destabilize edildiyse, artrodez iliak tespit ile veya iliak tespitsiz sakruma kadar uzatılır. Ancak, artrodezin sakruma kadar uzatılması kişisel hijyen ile ilgili problemler doğurabilir.

Pedikül vidalarının güvenli yerleştirilmesi teknik beceri ve akondroplazi hastalarının pedikül morfometrisi hakkında bilgiye bağlıdır. Akondroplazi hastalarında pediküllerin kraniyal inklinasyonu vardır ve vida yerleştirmek için başlangıç noktaları, lumbar vertebrada progresif olarak birbirinden ayrılır. Pedikül boyları bariz olarak kısadır ve yetişkin akondroplazi hastalarında alt torakal ve lomber pediküller için 20-25 mm uzunlukta pedikül vidaları uygundur. Yetişkinlerin çoğunda 5-7 mm çaplı pedikül vidaları kullanılabilir. Transvers açılanma en çok L5'te en az T12'dedir.

Ain ve Shirley, anterior enstrümantasyon ile yapılan iki basamaklı anterior ve posterior füzyon yapılan dört hastayı bildirdi. Düzeltme \%23-31 arasında idi ve hiç komplikasyon olmadı. Ain ve Brown, posterior spinal artrodez ( 7 hasta), posterior enstrümantasyon ile anteroposterior artrodez ( 2 hasta) ve anterior enstrümantasyon ile anteroposterior artrodez ( 3 hasta) yaptıkları toplam 12 hastayı (ortalama yaş 12,4-21 yıl) bildirdi. Tüm hastalarda füzyon başarı ile sağlandı 
ve cerrahi sırasında veya sonrasında hiç nörolojik komplikasyon olmadı. Ortalama cerrahi öncesi torakolomber kifoz $64^{\circ}\left(43-88^{\circ}\right)$ idi. Cerrahi sonrası torakolomber kifoz ortalama \%50 (\%17-73) düzelerek, $29^{\circ}\left(16-48^{\circ}\right)$ seviyesine geriledi.

Akondroplazi hastaları, spinal stenoz gelişimi açısından risk altındadırlar. Stenoz tipik olarak üçüncü veya dördüncü dekadda semptomatik hale gelir, ancak bulgular iskelet matüritesi olmamış hastalarda da görülmeye başlanabilir. Semptomatik spinal stenoz insidansı artarak, 10 yaşında \%10'dan altıncı dekadda \%80'e çıkar.

Akondroplazide spinal stenoz çeşitli nedenlere bağlı olarak gelişir. Enkondral ossifikasyon defekti, hem vertebra korpusunun hem de pediküllerin kısa olmasın neden olur. Pediküller ayrıca kalınlaşmıştır. İnterpediküler mesafe tipik olarak L1 den L5'e doğru azalır, ancak bu her hastada olmaz. Yumuşak doku elemanları da etkilenir ve intervertebral disklerde ve ligamentum flavumda hiperplazi görülür. Bu anomaliler, spinal kanalın sagittal ve koronal plandaki çapının \%40 azalmasına neden olur. Spinal kanalın daralmasına karşın medulla spinalis ve nöral elementler normal büyüklüktedir. Semptomlar progresif olduğunda veya konservatif tedaviye cevap alınamıyorsa, cerrahi dekompresyon endikasyonu doğar. Bilgisayarlı tomografi miyelografi ve MR preoperatif olarak elde edilir. Tekrarlayıcı stenozu ve ikincil cerrahi müdahaleyi önlemek için, dekompresyon stenoz seviyesinin en az üç seviye yukarısına ve altta en az S2'ye kadar uzanması gerekir. Nadiren toral kraniyospinal dekompresyon gerekebilir. Uematsu ve arkadaşlarının, akondroplazi hastalarının spinal dekompresyonunu rapor ettikleri çalışmada, 111 hastanın 13'üne (\%12) total kraniyospinal dekompresyon yapmak gerekmiştir. Cerrahi öncesi görüntüleme çalışmalarında lateral stenoz mevcutsa, her iki tarafta sinir kökleri eksplore edilerek geniş bir dekompresyon yapılır.

İskelet matüritesi tamamlanmamış akondroplazi hastalarında spinal stenoz dekompresyonunun komplikasyonları arasında; eksik iyileşme, dural yırtıklar, idrar disfonksiyonu, yara enfeksiyonu ve postlaminektomi kifozu sayılabilir.

Streeten ve ark., laminektomi yapılmış 20 akondroplazi hastasının 14'ünde nörolojik defisitin düzeldiğini rapor ettiler. Parapleji ve sfinkter disfonksiyonu gibi cerrahi öncesi şiddetli nörolojik defisitler, akut tedavi edilmedikleri sürece büyük ölçüde düzelmedi. Toplam 60 dekompresyon işleminin yapıldığı 44 pediatrik akondroplazi hastasında, Sciubba ve ark., olguların \%11'inde komplikasyon rapor ettiler. Bunların dördü dural yırtık, ikisi yara problemi ve biri enstrümantasyon yetmezliği idi. Altmış prosedürün 11 'i revizyon cerrahisiydi. Revizyon cerrahisi nedenleri arasında; füzyon olmamış vertebrada ilerleyen deformite (beş olgu), birleşke yeri stenozunda dekompresyon (beş olgu) ve aynı seviyete dekompresyon tekrarı (bir olgu) vardı. Her ne kadar Sciubba ve ark. \%7 olarak rapor etmiş olsalar da, dura ince ve kırılgan olduğu için, akondroplazi hastalarında dura yırtığı sıklığı yüksektir.

Postlaminektomi kifozu, iskelet matüritesi tamamlanmamış akondroplazi hastalarında sık görülen bir komplikasyondur, ancak yetişkinlerde o kadar sık değildir. Ain ve ark., 10 yıllık bir dönemde, semptomatik spinal stenoz nedeni ile $5-8$ seviye torakolomber laminektomi geçiren on iskelet matüritesi tamamlanmamış akondroplazi hastasını gözden geçirdiler. Ortalama cerrahi öncesi kifoz değeri $31^{\circ}\left(10-50^{\circ}\right)$ idi. Her ne kadar tüm mediyal fasetlerin \%50'den fazlası korunsa da, tüm hastalarda postlaminektomi torakolomber kifoz gelişti ve hepsi ilk cerrahiden 10 ay ila 2,6 yıl sonra sekonder artrodeze gitti. Postlaminektomi kifozu gelişmesi riski yüksek olduğu için, torakolomber laminektomi yapılan iskelet matüritesi tamamlanmamış akondroplazi hastalarına eşzamanlı spinal artrodez yapılması gerekmektedir.

\section{Diastrofik Displazi}

Diastrofik displazi, sülfat transport geninde mutasyon sonucu gelişir ve proteoglikan moleküllerinde negatif yüklü sülfat grupları bulunduğu için, öncelikle kıkırdağı etkiler. Otozomal dominant geçişlidir. Finlandiya dışında çok nadirdir. Belirtileri arasında; rizomelik kısalıkla birlikte belirgin boy kısalığı, otostopçu başparmağı, rijid pes ekinovarus, skewfoot, eklem kontraktürleri ve ileri derece osteoartrit sayılabilir.

Ortopedik olmayan bulgular arasında; yarık damak, trakelomalazi ve karnabahar kulak sayılabilir. Spinal bulguları; servikal kifoz, servikal spina bifida, skolyoz ve kifoskolyozdur.

Servikal kifoz, diastrofik displazi hastalarının üçte birinde görülür. Kifozun tipik olarak C3-C5 vertebra gövdelerinde hipoplazi ile birlikte C2-C3'te apeksi vardır. Hastaların \%80'inde servikal spina bifida da bulunur. Ancak, kifozun etiyolojisi spina bifidanın varlığına değil vertebra gövdelerinin hipoplazisine bağlıdır.

Diastrofik displazide servikal kifozun doğal seyri olumludur. Çocuklar başlarını dik tutmaya başlayıp ekstansör kaslarını güçlendirerek vertebraları üzerindeki stresi azalttıkça, kifozların çoğu düzelir. Mekanik yükün azalması, aynı zamanda vertebra hipoplazisinin 
düzelmesini de sağlar. Ancak, kifoz $60^{\circ}$ üzerinde, apikal vertebra yuvarlak veya üçgen şeklinde ve tamamen posteriora deplase ise progresyon muhtemeldir.

Genellikle tedavi gerekmez, ancak kifoz ilerliyorsa breys kullanılabilir. Bu hastalarda Milwaukee breys etkili olabilir. Nörolojik bulgu vasa veya breys kullanılmasına rağmen ilerleme devam ediyorsa, cerrahi tedavi endikasyonu vardır.

Diastrofik displazi hastalarında skolyoz son derece sıktır (\%90). Skolyoz gelişimi anolmal disk yapısı ve erken dejenerasyona bağlı olabilir. Bu hastalarda üç tip eğrilik vardır: hafif-ilerlemeyen, idiyopatik benzeri ve erken ilerleyen. Erken ilerleyen tip, infantil skolyozun progresif formuna benzer ve üç yaşından önce başlangıç, aşırı rotasyon ve hızlı ilerleme ile karakterizedir. Beraberinde kifoz olabilir. Tedavi edilmezse bu eğrilikler $100^{\circ}$ 'yi geçebilir. Tedavide, genç hastalarda uzayan rod enstrümantasyonu yapılırken, daha büyük hastalarda posterior spinal artrodezi ve/veya anterior spinal artrodezi uygulanır.

\section{Psödoakondroplazi}

Psödoakondroplazi, kıkırdak oligometrik matriks proteininin genideki mutasyon neticesi oluşur. Kıkırdak oligometrik matriks proteini, kondrositleri saran territorial matriksde bulunur; otozomal dominant geçer. Psödoakondroplazi, vertebranın, metafizlerin ve epifizlerin tutulumu ile karakterizedir. Belirtileri arasında; kısa boy, ekstremitelerin rizomelik veya mezomelik kısalı̆̆ı, bağ laksitesi, metafizlerde genişleme, epifizlerde küçülme ve fragmantasyon, kalça subluksasyonu, alt ekstremite dizilim bozukluğu ve narin yüz sayılabilir. Yük taşıyan eklemlerde ileri derece osteoartrit gelişir. Spinal bulguları, odontoid hipoplazi ve skolyozdur.

Psödoakondroplazi hastalarının \%60'ında os odontoideum vardır. Doğuştan eklem laksitesi ve os odontoideum bulunması, hastaların \%10-20'sinde atlanto-aksiyel instabiliteye yol açar. Psödoakondroplazi hastalarında skolyoz hafif derecedir. Eğriliği $25-45^{\circ}$ arasında olan skolyozlarda breys kullanılır. Eğrilikler çoğunlukla $50^{\circ}$ üzerine çıkmaz ve nadiren cerrahi gerekir. Cerrahi gerektiğinde, progresif respiratuvar kas paralizisi solunum yetmezliğine yol açabildiği için, cerrahi öncesi pulmoner değerlendirme gereklidir.

\section{Kollajen Sentezindeki Mutasyonlara Sekonder Displaziler}

Kollajendeki mutasyonlara sekonder birçok iskelet displazisi vardır. Spinal anomalilerle seyredebilen bu displaziler: Kniest displazisi, spondiloepifizyel displazi konjenita ve tarda ve metafizyel displaziler.
Kniest displazisi, orantısız kısa gövde ile karakterize Tip II kollajen $\alpha 1$ zincirindeki mutasyonun (COL2A1) neden olduğu, otozomal dominant bir hastalıktır. Belirtileri arasında; geniş metafizleri ve düzensiz displastik epifizleri olan dambıl şekilli uzun kemikler, eklem kontraktürleri, genu valgum ve ekinovarus ayak sayılabilir. Dejeneratif artrit, 10 yaşından itibaren gelişebilir. Ortopedik olmayan diğer belirtiler; midface hipoplazisi, miyopi, retinal ayrılma ve sağırıktır. Spinal belirtiler; odontoid hipoplazi, diğer servikal vertebraların hipoplazisi, tüm vertebraların düzleşmesi (platyspondyly), kifoz ve hafif derece skolyozdur. Platyspondyly birçok iskelet displazisinde görülür ve tedavi gerektirmez. Cerrahi müdahale gerektiğinde, hastaların pulmoner komplikasyonlara yol açabilecek yarık damak ve trakeomalazi açısından değerlendirilmeleri gerekir.

Spondiloepifizyelis konjenita ve tarda, spinal anomaliler ile seyredebilir. Spondiloepifizyelis konjenita, Tip II kollajendeki mutasyon (COL2A1) neticesinde oluşur. Otozomal dominant geçiş gösterir, ancak çoğu olgu yeni mutasyonlara sekonder gelişir. Bu aşırı nadir displazi; kısa gövde, kısa ekstremite, uzun kemik epifizlerinin anormal formasyonu ve alt ekstremite dizilim bozukluğu ile kendini gösterir. Diğer belirtileri; retinal ayrılma, aşırı miyopi ve sensörinöral işitme kaybıdır. Spinal belirtileri; atlanto-aksiyel instabilite, platyspondyly, kifoz ve skolyozdur. Atlanto-aksiyel instabilite, odontoid hipoplazisine veya bağ laksitesine sekonder olabilir. Bu hastalarda skolyoz hastalığın erken döneminde başlar ve breys tedavisine dirençlidir. Tedavi, $50^{\circ}$ üzerindeki eğrilikler için cerrahidir. Büyük eğrilikler veya aşırı kifoz için anterior greftleme ile birlikte anteroposterior füzyon gerekebilir.

Spondiloepifizyelis tarda, spondiloepifizyelis konjenitadan daha hafif seyreder. En sık X'e bağlı geçiş gösterir. Spondiloepifizyelis tarda, Tip II kollajendeki bir mutasyana bağlı gelişiyor olabilir, ancak mekanizma henüz gösterilememiştir. Belirtileri arasında; odontoid hipoplazi, hafif platyspondyly, skolyoz ve osteoartrit sayılabilir.

Spinal problemler metafizyel kondrodisplazi hastalarında da görülebilir. Bu grup hastalıklar, epifizin tutulmadığı, metafizin etkilendiği, kısa boy ve genu varum ile seyreden rahatsızlıklardır. Schmid tipi Tip $\mathrm{X}$, kollajenin $\alpha$ zincirinin mutasyonu (COL110A1) neticesi gelişir. Otozomal dominant geçiş gösterir. McKusick tipi, ayrıca kıkırdak-saç hipoplazisi olarak da bilinir ve RMRP geni (mitokondriyal ribozomal nükleik asit işleyen endoribonükleazın ribozomal nükleik asit komponenti) mutasyonu neticesi oluşur. Belirtileri arasında; bağ laksitesi, pektus anomalileri, ince saç, $T$ hücre immünitesi bozukluğu, anemi, 
Hirschprung hastalığı ve artmış malignensi riski sayılabilir. Bu iki tip metafizyel kondrodisplazide de atlanto-aksiyel instabilite görülebilir.

\section{Mukopolisakkaridozlar}

Mukopolisakkaridozlar, enzimatik noksanlıktan kaynaklanan bir grup lizozomal depo hastalığıdır. Genetik geçiş X'e bağlı olan Tip II (Hunter sendromu) dışında otozomal resesiftir. Belirtiler her tip için değişiklik gösterir. Genel olarak bu displaziler, kısa boy, sert eklem ve geniş asetabulum ile karakterizedir. En sık görülen tipler Tip I ve Tip IV'tür.

Mukopolisakkaridoz Tip I, Hurler ve Scheie altgruplarına ayrılır; Hurler ağır formu, Scheie hafif formudur. Hurler sendromu, ilerleyen mental retardasyon, ileri derece deformiteler ve organ disfonksiyonları ile karakterizedir. Ölüm 10 yaşından önce gerçekleşir. Scheie formu ise eklem katılığı, ekstremite dizilim bozukluğu ve normal hayat süresi ile karakterizedir. Her iki formda da odontoid hipoplazi ve atlanto-aksiyel instabilite gibi üst servikal anomaliler görülebilir.

Morquio sendromununda (Tip IV) kornea, kıkırdak ve intervertebral disklerin nükleus pulpozusunda bulunan keratan sülfatın parçalanmasında defekt vardır. Bu defektif parçalanma, korneada opasitelere ve idrarda keratan sülfat salınmasına yol açar. Diğer belirtileri; kısa gövdeli cücelik, genu valgum, bağ laksitesi ve erken kalça ve diz artritidir. Spinal belirtileri platyspondyly, odontoid hipoplazisi, atlanto-aksiyel instabilite ve skolyozdur.

Tüm Morquio hastalarında odontoid hipoplazisi vardır. Atlanto-aksiyel instabilite, gecikmiş motor gelişmeye yol açan miyelopatiye neden olabilir. Motor gelişmedeki bu gecikme yanlışlıkla genu valguma bağlanabilir. Atlanto-aksiyel instabilite cerrahi müdahaleyi gerektirdiğinde, pulmoner hipertansiyonu ve kardiyak anomalileri ekarte etmek için cerrahi öncesi solunum ve dolaşım sistemi değerlendirilmesi yapılmalıdır. Restriktif akciğer hastalığı, uyku apnesi veya pumoner hipertansiyon bulunabilir. Kardiyak tutulumda, aort yetmezliği veya koroner arterlerin mukopolisakkaridlerle infiltrasyonu nedeniyle koroner iskemi gözlenebilir. Atlanto-aksiyel instabilite ile birlikte anterior hipertrofik yumuşak doku kitlesi bulunabilir. Posterior füzyon başarı ile gerçekleştirildikten sonra yumuşak doku kitlesi kaybolur. Bu nedenle, ilk cerrahide anterior dekompresyon her zaman yapılmaz.

\section{Diğer İskelet Displazileri}

Spinal belirtiler veren diğer iskelet anomalileri; kondrodisplazi punktata, Larsen sendromu, metotropik cücelik ve spondilometafizyel displazidir.
Konjenital benekli epifiz olarak da bilinen kondrodisplazi punktata birçok alt tipe sahiptir. Nedeni, defektif kolesterol sentezi ile ilişkilidir. Belirtileri; kısa gövde, yüz anomalileri ve radyolojik beneklenmelerdir. En sık rastlanan alt tipi Conradi-Hünermann sendromudur. Conradi-Hünermann sendromunun spinal belirtileri; atlanto-aksiyel instabilite, skolyoz, kifoz ve spinal stenozdur. Servikal stenoz gelişebilir, ancak nadirdir. Skolyoz iki şekilde görülür: displatik vertebra ile birlikte olmayan yavaş ilerleyen skolyoz ve displastik vertebra ile birlikte olan, hızlı ilerleyen skolyoz ve kifoskolyoz. Yavaş ilerleyen skolyoz için cerrahi müdahale gerektiğinde posterior artrodez yeterli olacaktır. Hızlı ilerleyen tipte psödoartroz riskini önlemek için, sıklıkla anteroposterior füzyon yapmak gerekir. Hemiepifizyodez, displastik vertebra ile seyreden diğer konjenital deformitelerde olduğu kadar fayda etmez, çünkü bu hastalarda tüm vertebralar potansiyel olarak displastiktir. Cerrahi müdahale gerektiğinde, potansiyel konjenital anomaliler nedeni ile, cerrahi öncesi kardiyak ve renal fonksiyonlar değerlendirilmelidir.

Larsen sendromu, multipl eklem dislokasyonları, hipertelörizm ve hipotoni ile karakterizedir. Dislokasyonlar sıklıkla dirsek, kalça ve dizde olur. Genetik geçiş, otozomal dominant veya otozomal resesiftir. Gözlemlenebilecek spinal problemler; servikal kifoz, servikal/torasik spina bifida, atlanto-aksiyel instabilite, subaksiyel instabilite, spondilolistezis ve skolyozdur. Larsen sendromu hastalarının \%60'ında servikal kifoz gözlenir. Kifoz C4 ve C5'teki hipoplastik vertebra korpuslarından kaynaklanır. Servikal kifoz ve diastrofik displazi hastalarının tersine, kifozun spontan düzelmesi görülmez. Kifoz açısı $40^{\circ}$ üzerinde olanlarda, posterior spinal artrodez endikasyonu vardır. Artrodezden sonra, çocuk büyüdükçe füzyon kitlesi posteriordan uzamaya engelleyici olacağı için, ek düzeltmeler yapılması gerekebilir.

Metatrofik cücelik, kifoz ve skolyoz geliştikçe kısa gövde cüceliğine dönen, kısa ekstremite cüceliği ile karakterizedir. Genişlemiş metafizler ve eklem kontraktürleri görülür. Omurga boyunca vertebralar düzleşmiştir. Kifoz ve skolyoza ek olarak atlanto-aksiyel instabilite gelişebilir. Metatrofik displazide, skolyoz karakteristik olarak rijiddir. Cerrahi tedavide, anterior gevşetmeyi takiben posterior spinal artrodez yapmak gerekebilir. Cerrahi müdahale gerektiğinde, pulmoner yetmezlik olabileceğinden pulmoner değerlendirme gereklidir.

Spondiloepimetafizyel displazi, yaygın vertebra, metafiz ve epifiz tutulumu ile karakterize, nadir bir displazidir. Ileri derecede kifoskolyoz gelişebilir. Kifoskolyoz, hayatın ilk iki yılında ortaya çıkabilir ve 
hızla ilerleyerek parapleji ve kor pulmonaleye yol açabilir. Cerrahi tedavisi zorludur ve sıklıkla anteroposterior spinal artrodez gerekir.

\section{SONUÇ}

İskelet displazisi hastalarında spinal belirtiler sıktır. Bunların arasında; atlanto-aksiyel instabilite, servikal kifoz, torakolomber kifoz, skolyoz, foramen magnum stenozu ve spinal stenoz sayllabilir. Bu problemlerin doğal seyri ve tedavisi, beraber görüldüğü iskelet displazisine göre değişkenlik gösterir.

\section{KAYNAKLAR}

1. Ain MC, Shirley ED. Spinal Manifestations of the Skeletal Dysplasias. In: Akbarnia BA, Yazıcı M, Thompson GH. The growing spine: management of spinal disorders in young children, Vol. XXV. Heidelberg/New York: Springer; 2011. p.177-86.

2. Sanders JO. Spinal deformity in skeletal dysplasias. Spine Deformity 2012. Crossref

3. Shirly ED, Ain MC. Spinal Deformity in Skeletal Dysplasia Conditions. In: Bridwell KH, DeWald RL, editors. The textbook of spinal surgery. Philadelphia: Lippincott Williams \& Wilkins; 2011. p.1084-98.

4. Tolo VT. Spinal Deformity in Skeletal Dysplasia. In: Weinstein $\mathrm{SL}$, editor. The pediatric spine: principles and practice. New York: Raven Press;1994. p. 369-92. 